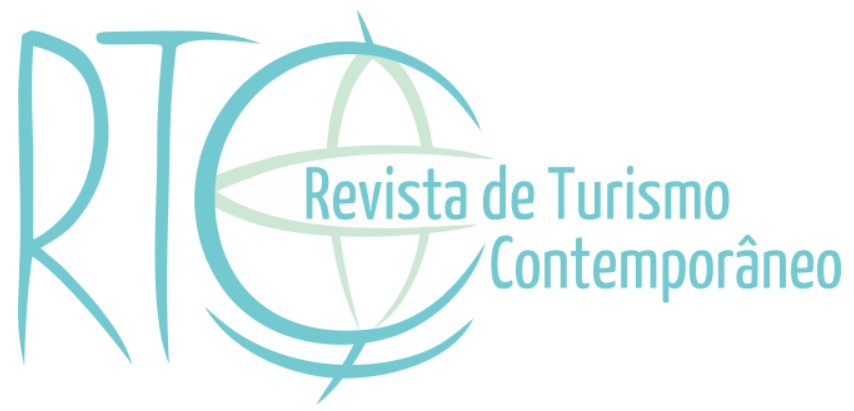

\title{
Estratégias competitivas praticadas por empresas de organização de eventos de Curitiba e região metropolitana - $\mathbf{P R}^{1}$
}

\section{Competitive strategies practiced by event organization companies in Curitiba and metropolitan region - PR}

\section{Marcos Rogério Maioli}

Professor do Curso Técnico em Eventos, Curso de Logística e Meio Ambiente na modalidade EaD e do Curso de Graduação em Gestão Pública do Instituto Federal do Paraná - IFPR, Curitiba/PR, Brasil

E-mail:marcos.maioli@ifpr.edu.br

\section{Carlos Alberto Tomelin}

Professor do Programa Stricto Sensu - Mestrado e Doutorado - em Turismo e Hotelaria da Universidade do Vale do Itajai - UNIVALI, Santa Catarina/SC, Brasil

E-mail: tomelin@univali.br

${ }^{1} \mathrm{O}$ artigo possui o apoio da CAPES (Coordenação de Aperfeiçoamento de Pessoal de Nível Superior) 


\section{RESUMO}

Temas relacionados às estratégias competitivas têm sido cada vez mais abordados por pesquisadores que buscam indicativos do comportamento organizacional realizado por empresas frente a um ambiente mutável. A competição entre as organizações faz com que aquelas que não conseguem se adaptar a mudanças tenham dificuldades em sobreviver no mercado. O objetivo deste estudo foi analisar a influência das estratégias competitivas nas formas de gestão das empresas de eventos da cidade de Curitiba-PR e Região Metropolitana. O estudo é do tipo exploratório-descritivo, com análises quantitativas, e se deu por meio de aplicação de instrumento de coleta de dados junto a gestores de empresas organizadoras de eventos baseado nas estratégias competitivas de Porter, Ansoff e Miles e Snow. A estratégia mais indicada pela média de homogeneidade foi a estratégia de diversificação de Ansoff, e a segunda e terceira foram as estratégias de Miles e Snow de atitudes analíticas e atitudes prospectivas. Como principais resultados aferiu-se que as empresas utilizam estratégias de forma aleatória e não vinculadas a um planejamento estratégico formulado e discutido para obter o maior retorno e uma maior aplicabilidade com possibilidade de retorno na resolução de problemas. Percebe-se que devido à concorrência cada vez mais acirrada as empresas que subsidiam suas decisões em estratégias já consolidadas possuem fatores de sobrevivência em longo prazo.

Palavras-chave: Empresas de eventos. Estratégia de competitividade. Gestão de empresas.

\section{ABSTRACT}

Issues related to competitive strategies have been increasingly addressed by researchers, who look for indicators of organizational behavior carried out by companies facing a changing environment, the competitiveness between organizations makes those organizations that can not adapt to organizational changes, have difficulties to survive in the market. The objective of this study was to analyze the influence of competitive strategies on the management of event companies in the city of Curitiba, PR and metropolitan region. The study is of the exploratory-descriptive type with quantitative and qualitative analyzes and will be done through the application of an instrument of data collection with managers of companies that organize events based on the competitive strategies of services of Porter, Ansoff and Miles and Snow, the strategy most indicated by the average homogeneity was the strategy of Ansoff diversification and the second and third were the strategies of Miles and Snow of analytic attitudes and prospective attitudes. Companies use strategies at random and not linked to strategic planning formulated and discussed to obtain the highest return and greater applicability with possibility of return in problem solving. It is noticed that due to the increasingly fierce competition, the companies that subsidize their decisions in already consolidated strategies have survival factors in the long term.

Keywords: Event Companies. Competitiveness Strategy. Business management. 


\section{INTRODUÇÃO}

As empresas de eventos, assim como outros setores, possuem regulações que são definidas pelo governo e mediadas pelo mercado, necessitando de um plano estratégico que obrigue à definição clara de metas, objetivos e propósitos.

A relevância atual do turismo de eventos no mundo, aliada à concorrência acirrada em uma economia globalizada, faz com que haja disputas entre empresas para organizar determinados eventos, envolvendo, desta forma, uma contenda entre elas, com grande investimento de tempo, dinheiro e trabalho dos mais diferentes profissionais. Estes fatores, aliados a outros como a criatividade, a imagem da empresa, a competência e a inovação, contribuem para que empresas de eventos se destaquem, conquistem novos mercados e assumam novos projetos, sobrevivendo assim em um cenário cada vez mais competitivo.

A importância de se fazer um estudo relacionado às estratégias competitivas é direcionar e esclarecer o leitor sobre como conduzir o planejamento de uma empresa de eventos de forma que possa atuar com maior eficiência e produtividade, gerando dividendos positivos e sustentabilidade empresarial.

Segundo o Cadastro de Prestadores de Serviços Turísticos do Ministério do Turismo (CADASTUR $^{2}$ ), criado pela Portaria $\mathrm{n}^{\mathrm{o}}$ 130, de 26 de julho de 2011, pelo Ministério do Turismo, que institui o CADASTUR, existem 59 empresas organizadoras de eventos em Curitiba e Região Metropolitana.

Devido ao grande número de empresas, discorre-se a relevância uma vez que aborda de forma mais específica o tema a partir de duas perspectivas: a acadêmica e a organizacional. No lado acadêmico a contribuição é percebida pela forma de acarear a teoria com a prática, além de aprofundar os estudos sobre o tema. Por outra vertente, a organizacional, o estudo fornece subsídios para que o setor das empresas de organização de eventos tome decisões assertivas sobre estratégias competitivas.

\section{REFERENCIAL TEÓRICO}

A atividade turística se dá pela movimentação de pessoas (Organização Mundial de Turismo [OMT], 2011) em busca de localidades que tenham algum tipo de atrativos, impactando economicamente e contribuindo para diversificar a economia de uma localidade, região ou país (Goeldner, Ritchie, \& Mcintosh, 2002; Jarvis \& Blank, 2011).

\footnotetext{
${ }^{2}$ Cadastro de pessoas físicas e jurídicas prestadores de serviços turísticos e é obrigatório para empresas de organização de eventos. Fonte: http://www.classificacao.turismo.gov.br/MTUR-classificacao/mtursite/cadastur.jsp
} 
O fato de atrair investimentos e trazer o desenvolvimento para localidades, e também impostos, empregos e renda, acirra a competitividade para os planejadores e gestores do turismo. Para a Organização Mundial do Turismo (OMT, 1998), o turista é aquela pessoa que não realiza atividades econômicas e habita determinado lugar por tempo inferior a um ano. Um dos segmentos mais importantes relacionados ao fluxo turístico é o de realização de eventos, já que grandes fluxos turísticos são ocasionados graças à existência deste segmento (Coutinho \& Coutinho, 2007; Zan, 2011).

Um evento é o encontro de pessoas, em data e local programado, com interesses em comum, com objetivos claros a serem buscados (Zanella, 2003; Getz, 2008; Zoboran, 2012; Nakane, 2013; Stadler, Arantes \& Rodermel, 2013), servindo para combater a sazonalidade (Zan, 2011; Canton, 2002), movimentando a economia (Carneiro, 2011), gerando empregos (Reis, 2013), auxiliando no desenvolvimento local e regional (Ziakas \& Costa, 2011).

Normalmente de duração limitada e com objetivos definidos, mas sem frequência determinada (Lawson, 2000), constitui uma opção ao Marketing, pois congrega no mesmo espaço pessoas interessadas no tema, podendo ainda alguns tipos de eventos serem usados para instruir, treinar e incentivar (Ferreira \& Wada, 2010) pessoas, empresas públicas e privadas.

$\mathrm{O}$ ato de organizar um evento indica características típicas da configuração de um projeto (Pereira \& Borges, 2006; Canton, 2002), sendo um serviço de valor (Zan, 2011), devendo gerar retorno sobre o investimento (Getz, 2008) e movimentar a economia local com a vinda de turistas (Carneiro, 2011). Estimulando a criação de empregos (Reis, 2013) com aproveitamento da mão de obra local (Zanella, 2003), geram impostos, combatem a sazonalidade, utilizam serviços turísticos e contribuem para o desenvolvimento de novos serviços.

Em resumo, um evento não tem aspectos fátuos, é o resultado do esforço concentrado em unir, em um determinado lugar, um público específico, para que em conjunto assista a realização de atividades programadas antecipadamente e determinadas a alguma função, por certo período de tempo, levado pelos mais diferentes tipos de objetivos.

No Brasil conforme pesquisa divulgada no II Dimensionamento Econômico da Indústria de Eventos do Brasil 2013, realizada pelo Serviço Brasileiro de Apoio às Micro e Pequenas Empresas (SEBRAE) e pela Associação Brasileira de Empresas de Eventos (ABEOC Brasil) junto a mais de 2700 empresas organizadoras de eventos brasileiras, o mercado de eventos no Brasil tem crescido em média 14\% ao ano. Dados de 2013 indicam 
uma movimentação de R 209,2 bilhões, representando participação de 4,32\% no Produto Interno Bruto (PIB) do país.

Em 2013, o Brasil sediou aproximadamente 590 mil eventos, com a participação de 202,2 milhões de pessoas, com gasto médio individual de $\mathrm{R} \$ 161,80$, somando um total de $\mathrm{R} \$$ 99,3 bilhões. As empresas organizadoras de eventos lucraram R \$ 59 bilhões, de acordo com o II Dimensionamento Econômico da Indústria de Eventos do Brasil (2013). (ABEOC, 2014).

Historicamente o uso do termo estratégia está diretamente relacionado ao campo militar, já que é derivado da palavra grega strategos, que significa aquilo que o general fez (Oliveira, 1991). Ansoff (1977, p. 99) afirma que a "origem histórica pode ser situada na arte militar, onde é um conceito amplo, vagamente definido, de uma campanha militar para aplicação de forças em grande escala contra um inimigo". Para Nescheim (2007, p. 141) "a lista básica de estratégias empresariais baseia-se no pensamento militar”.

Os modelos de estratégias competitivas existentes não estão vinculados a um setor econômico específico e são genéricos, podendo ser adaptados a diversas áreas econômicas, como é o caso do Modelo Diamante da Competividade, de Porter (1990). As vantagens competitivas que uma organização possui contribuem para a escolha da melhor estratégia a ser utilizada, aquela que em tese trará melhor desempenho e auxiliará a organização a atingir suas metas e conquistar seus objetivos (Porter, 1990; Wright, Kroll, \& Parnell, 2000; Whittington, 2004; Bernardi, 2003; Barbosa \& Teixeira, 2003; Barney \& Clark, 2007; Forsythe, 2008).

A escolha da estratégia competitiva a ser adotada pela organização deve priorizar a proposta de um conjunto de atividades diferentes daquelas dos concorrentes, para atingir objetivos concretos e mensuráveis, posicionando-se estrategicamente em diferentes formas (Ansoff, 1977; Porter, 1990; Whittington, 2004; Barney \& Clark, 2007; Forsythe, 2008).

O Modelo de Porter (1990) explica que a atratividade da indústria e a rentabilidade de determinados setores a longo prazo estão diretamente relacionadas a cinco forças determinantes: rivalidade entre competidores, ameaças de substituição, poder de negociação dos compradores, poder de negociação de fornecedores e ameaças da entrada de novos concorrentes no mercado.

As ameaças de substituição, segundo Gohr, Moretto Neto e Santana (2002, p. 52), ocorrem em um setor "se todas as empresas estão competindo com outras que produzem produtos substitutos, os substitutos podem reduzir o retorno das empresas". Já tratando do poder de negociação dos fornecedores, Hocayen-da-Silva e Teixeira (2011, p. 04) afirmam 
que "caracteriza-se pela possibilidade de aumento dos preços ou redução da qualidade, ocasionando queda na rentabilidade do setor”.

Sobre o poder de negociação dos compradores, Brasileiro e Morandi (2014, p. 31) afirmam que "pode reduzir os lucros das organizações ao exigir melhor qualidade dos produtos ou cobrar por uma prestação de serviços mais adequada, atendendo seus anseios, exigindo mais qualidade e serviços agregados".

A respeito de novos entrantes, Jaffe, Nebenzahl e Schorr (2005) afirmam que a entrada de concorrente pode ameaçar a empresa e sua participação no mercado.

Porter (1990) indica as três estratégias competitivas, aqui apresentadas de forma resumida:

Liderança em custos - quando a empresa produz em grande volume para minimizar gastos busca uma posição de baixo custo que a protege contra todas as forças competitivas. Sua busca está diretamente relacionada com os custos.

Diferenciação - busca diferenciar o produto ou o serviço oferecido pela empresa, disponibilizando algo único, investindo em imagem e marca, proporcionando margens de lucro maiores. A diferenciação está relacionada também à exclusividade, o que faz com que a parcela de clientes a ser atendida seja pequena.

Enfoque - busca escolher um determinado grupo comprador ou segmento/nicho específico. Atinge o objetivo quando satisfaz as necessidades dos clientes atendidos por diferenciação ou custos.

O modelo da Tipologia Genérica, de Ansoff (1991), indica que existem duas formas de estratégias competitivas que podem ser usadas pelas empresas: As Estratégias de Expansão estão ligadas à penetração no mercado, ao desenvolvimento de mercados e ao desenvolvimento de produtos. As Estratégias de Diversificação estão ligadas a oportunidades de diversificação horizontais, verticais e concêntricas (Ansoff, 1990; Long \& Perdue, 1990).

Estas estratégias deram origem às quatro estratégias que podem ser usadas pelas empresas, que, segundo as definições de Ansoff (1997, p. 41), podem ser:

a) Penetração no mercado denota uma direção de crescimento por meio do aumento da participação relativa da empresa nas suas linhas correntes de produtos e mercados.

b) Desenvolvimento de mercados, a empresa busca novas missões para os seus produtos atuais.

c) Desenvolvimento de produtos representa o processo pelo qual a empresa cria novos produtos para substituir os já existentes.

d) Diversificação, a empresa busca novos produtos e novas missões. 
Estas estratégias buscam responder como e porque as organizações, seja na tecnologia ou em sua maneira de gerir as dificuldades, assumem diversas estratégias para competir no mercado, e chega à conclusão que elas se diferenciam das demais utilizando quatro estratégias de adaptação: defensivas, prospectivas, analíticas e reativas, adotando uma linha de produtos limitada, segmentada e mais lucrativa (Zahra, Pearce II, 1990).

As estratégias defensivas procuram resolver problemas por meio de soluções na organização com suporte vertical na empresa, fazendo com que instruções e normas venham de cima para baixo e relatórios e explicações, de baixo para cima (Miles \& Snow, 1978; Gimenez, Pelisson, Kruger \& Hayashi Jr, 1999).

As estratégias prospectivas buscam facilitar as oportunidades com inovação de produtos e processos, podendo comprometer a eficiência (Miles \& Snow, 1994; Charles, Snow, Lawrence, \& Hrebiniak, 1980; Hambrick, 1984).

As organizações analíticas buscam se adaptar a variações de produto e do mercado em que estão inseridas, um híbrido das estratégias defensivas e prospectivas (Miles \& Snow 1994; Hambrick, 1984).

As reativas são aquelas empresas que não usam nenhuma estratégia viável, atuam de forma instável no mercado, não usando estratégias e não conseguindo fazer frente às mudanças do mercado em que estão inseridas (Miles \& Snow, 1978).

\section{METODOLOGIA}

O presente estudo trata de uma pesquisa survey com cunho quantitativo pertencente ao paradigma positivista, com caráter exploratório e descritivo. Os dados obtidos com o levantamento bibliográfico foram usados para subsidiar a fundamentação teórica do presente trabalho, sendo escolhidas as teorias dos 3 autores mais citados na área de estratégia.

Os questionários foram baseados nos construtos das teorias de competitividade Diamante, de Porter (1986), Ansoff (1991) e Miles e Snow (1978), no estilo survey, que trata da caracterização da empresa, possuíam 10 questões abertas e 10 questões fechadas, que tratam de informações sobre o gestor e a empresa. Depois em específico sobre competitividade com 13 diferentes estratégias competitivas, cada qual com 5 afirmativas em um total de 65 afirmativas, através da escala de Lickert, o entrevistado respondeu qual a sua concordância (baixa, média ou alta) em relação às afirmativas.

Entre julho e setembro de 2016 foram entrevistados os gestores de empresas organizadoras de eventos de Curitiba e Região Metropolitana, selecionadas a partir da lista do CADASTUR. Das 59 empresas inicialmente, 4 fecharam ou encerraram as operações de 
eventos; 5 estavam com dados repetidos (empresas com vários nomes e CNPJ que ficam no mesmo endereço e possuem o mesmo número de telefone); e 1 empresa informou que não é organizadora de eventos, somente fornecedora de serviços para eventos (cadastrada erroneamente como organizadora). 4 continham dados incorretos e não foi possível localizar. 6 empresas se recusaram a responder o questionário, sendo a amostra de respondentes entrevistados de 39 empresas.

Os questionários foram enviados via internet e 13 deles foram coletados pessoalmente nas empresas dos entrevistados. Os resultados encontrados foram tabulados por meio de estatística descritiva, multivariada e foi utilizada a escala de Lickert de sete pontos. Os resultados foram analisados pela classificação de Alpha de Cronbach, que mede a confiabilidade no instrumento de coleta. A confiabilidade reflete o quanto de certeza é possível assumir que o instrumento possui ao medir o que se propõe. Se um instrumento de medida apresenta sempre os mesmos resultados quando aplicados a indivíduos estruturalmente semelhantes, o resultado é, portanto, uma boa estimativa (Cronbach, 1951).

\section{ANÁLISE E DISCUSSÃO DOS RESULTADOS}

A análise dos dados do questionário que caracterizou o perfil do setor de eventos de Curitiba e Região Metropolitana, conforme os objetivos específicos deste trabalho. Buscou-se o aprofundamento da análise, realizando cruzamentos entre as variáveis, a partir de tabulações simples conforme o Quadro 1, e para estes cruzamentos aplicou-se o teste G ou o quiquadrado para verificação de atendimento a requisitos mínimos de confiabilidade.

Quadro 1 - Cruzamentos das Variáveis

\begin{tabular}{|l|l|}
\hline \multicolumn{1}{|c|}{ Variável 1 } & \multicolumn{1}{c|}{ Variável 2 } \\
\hline Cargo profissional do entrevistado & Tempo no trabalho (categorizada) \\
\hline Projeção de crescimento ao ano & Tempo de trabalho com eventos do entrevistado \\
\hline Cargo profissional do entrevistado & Projeção de crescimento ao ano \\
\hline Cargo (função) do entrevistado & Tipo de gestão \\
\hline Cargo (função) & Porte da empresa \\
\hline Maneira como identifica a marca da empresa & Tempo máximo que trabalha com eventos \\
\hline Produtos ofertados pela empresa & Produto procurado pelo mercado \\
\hline Número máximo de eventos realizados ao ano & Número de funcionários diretos \\
\hline
\end{tabular}

Fonte: Elaborado pelos autores, 2016.

A partir da amostra pesquisada, verificou-se que os cargos de atuação dos respondentes são de gestores de nível executivo e gerencial, sendo 23 diretores, sete sócios proprietários e nove atuantes em áreas gerenciais.

Constata-se, ainda, que todos ocupam atividades estratégicas nas organizações em que atuam. Funções estas caracterizadas pela gestão do negócio e na tomada de decisões 
relacionadas ao planejamento, ao Marketing, à comercialização e ao desenvolvimento de serviços e produtos, indicando que existe uma confiabilidade maior nos respondentes, pois tomaram e tomam decisões que representam a forma de gerir a empresa. Baseados no conhecimento adquirido em administrar as organizações conseguem responder com maior presteza e assertividade ao questionário aplicado.

Quanto ao tempo de atuação na função de organizadores de eventos, 56,5\% dos entrevistados, ou seja, a maioria, demonstram ter uma experiência superior a 6 anos, em muitos casos chegando acima de 12 anos, e somente 45,4\% deles atuam por um período menor de 6 anos. Estes dados indicam que os gestores possuem de média a alta experiência em suas funções, fato que reforça, mesmo que de forma empírica, a visão sobre estratégias competitivas como ferramenta de gestão no cotidiano da organização.

Já sobre o tempo que o entrevistado trabalha diretamente com eventos, da mesma forma é possível verificar sua relevante experiência no ramo, haja vista que 10 deles atuam entre 1 a 8 anos no mercado; 13 deles, entre 8 e 15 anos; 9, entre 15 e 21 anos, e 7 deles atuam há mais de 21 anos na área de eventos. A experiência dos respondentes com eventos é percebida positivamente neste estudo, pois há maiores possibilidades de que já tenham elaborado estratégias competitivas durante esse tempo ou participado do processo de formação de estratégias.

A partir da caracterização do perfil dos entrevistados, buscou-se cruzamentos de informações e entre o perfil e dados das empresas pesquisadas.

$\mathrm{Na}$ verificação do cruzamento entre o cargo (função do entrevistado) e a variável tempo de trabalho, o destaque ficou para o cargo de Diretor, pois 4 deles atuam entre 1 e 8 anos na função; 10 diretores atuam entre 8 e 15 anos na função; 4 deles, entre 15 e 21 anos na função; 2 diretores, entre 21 e 28 anos na função; e 3 deles, entre 28 e 35 anos na função, somando um total de 23 , ou seja, $58,97 \%$.

Conclui-se que nas empresas onde existe o cargo de Diretor existe uma permanência por mais tempo na função exercida. Chiavenato e Sapiro (2009) apontam que empresas que possuem colaboradores por mais tempo conseguem planejar melhor suas atividades e atingem seus objetivos com maior facilidade.

$\mathrm{O}$ teste $\mathrm{p}$-valor foi realizado para verificar se as categorias diferem em relação a alguma característica. Como o p-valor foi alto $(0,4616)$ o resultado da estatística calculada está na região de aceitação do teste; assim, aceita-se a hipótese nula. E neste caso, a conclusão é que estas informações não estão associadas, ou seja, não têm influência conjunta e a 
conclusão é que as variáveis não estão associadas. A hipótese de nulidade sempre diz que não há diferença no número esperado de escolhas.

Dados similares podem ser encontrados quando se faz um novo cruzamento agora entre o crescimento ao ano associado à variável tempo de trabalho com eventos.

Sobre a taxa de crescimento ao ano da empresa organizadora de eventos, 24 (61,54\%) indicaram que a empresa se encontra estabilizada; 3 responderam que a empresa cresceu em média $1,6 \%$ a $2 \%$ ao ano; outras 3 empresas cresceram em média $2,6 \%$ a $3 \%$ ao ano; outras 3 empresas cresceram entre 3,6\% e $4 \%$ ao ano; 2 empresas cresceram entre 0,5\% e 1,5\% ao ano; 2 empresas cresceram entre $2,1 \%$ e $2,5 \%$ ao ano; e 2 empresas cresceram entre $3,1 \%$ e $3,5 \%$ ao ano. Nenhuma das empresas cresceu mais de $4,1 \%$ ao ano.

Como o quadro recessivo de 2014 apresentou crescimento pífio de 0,2\%, que se intensificou em 2015, com queda no PIB brasileiro de 3,8\% ao ano, que fechou 2016 com retração estimada em 2,8\% (Folha de São Paulo, 2016; IBGE, 2016; Valor Econômico, 2016), a experiência dos gestores das empresas de eventos foi fator crucial para mantê-las em operação. Mesmo com pouco ou nenhum crescimento, mantiveram o empreendimento aberto, possibilitando que não sucumbisse conforme é percebido em um comparativo entre a quantidade de empresas que estavam no CADASTUR em 2014 (71) e as que continuavam operando em 2016 (49) (CADASTUR, 2016).

Observou-se que dos 39 entrevistados, 34 possuem curso superior nas mais variadas formações $(87,1 \%)$ e 5 deles possuem formação de nível médio ou técnico, fato este que demonstra que profissionais de diferentes formações como gestores, atuam em funções estratégias no mercado de eventos. Quanto àqueles que possuem pós-graduação, 13 deles têm essa formação em marketing; 8, em planejamento e gestão; 3, em gestão estratégica; 2, em eventos; 1 , em comunicação institucional; 1 , em tutoria online; 1 , em recreação e lazer.

A maioria dos cursos, tanto de graduação quanto de pós-graduação, é na área de gestão, fato que fornece conhecimentos e subsídios teóricos que permitem a estes gestores tomarem decisões adequadas e necessárias para que a empresa continue operando de forma profissional. Isso contribui para a visão de negócios e de performance que as empresas vêm demonstrando, haja vista o índice de crescimento e estabilização frente à crise econômica atual.

O cruzamento indica que os respondentes com formação na área de gestão (Administração, Turismo, Gestão Comercial) possuem indicadores de crescimento acima da média, podendo ser considerados bons estrategistas e que conseguem manter a empresa e prosperar. 
O mercado de eventos no Brasil encontra-se com retração acentuada em 2014 e 2015, com estimativa de repetição dessa perspectiva em alguns mercados em 2016 já que a previsão do PIB é uma retração de 2,8\% (Instituto Brasileiro de Geografia e Estatística [IBGE], 2016), após 11 trimestres de recessão (IBGE, 2016), segundo dados do setor de eventos (Associação Brasileira de Empresas de Eventos [ABEOC NACIONAL], 2014).

Para caracterizar o perfil das empresas organizadoras de eventos na cidade de Curitiba e Região Metropolitana, constatou-se que o tipo de gestão da empresa organizadora de eventos é na maioria dirigida de forma profissional. Quanto ao número de funcionários diretos, a maioria tem até 5 funcionários. O principal segmento de eventos atendido é, nesta ordem, congressos e conferências, feiras, formaturas e casamentos. A média de eventos organizados por ano foi de até 50, apenas 1 empresa realiza mais de 150 eventos por ano.

Sobre os produtos e serviços ofertados no mercado, a maioria oferece a organização de eventos e pratica preços médios em relação aos concorrentes. Em relação à maior preocupação da empresa organizadora de eventos durante a prestação de serviços, o destaque é a qualidade do serviço. Já sobre a compra de produtos utilizados pela empresa, o maior indicativo foi a qualidade, deixando os preços em último lugar.

A partir deste perfil é possível seguir para identificar e verificar as estratégias competitivas praticadas pelas empresas de eventos da amostra.

O Quadro 2 a seguir apresenta a relação por ordem de respostas por homogeneidade das estratégias, elaborada de acordo com as respostas de maior homogeneidade nos 13 blocos do questionário aplicado. Os dados respondem os objetivos específicos, que procuraram descobrir quais as teorias mais usadas.

Quadro 2 - Relação por Ordem de Resposta por Homogeneidade das Estratégias

\begin{tabular}{|c|l|l|}
\hline Classificação & Teoria e Autor & Estratégia \\
\hline $1^{\text {a }}$ & Ansoff & Diversificação \\
\hline $2^{\text {a }}$ & Miles e Snow & Atitudes analíticas \\
\hline $3^{\text {a }}$ & Miles e Snow & Atitudes prospectivas \\
\hline $4^{\text {a }}$ & Ansoff & Penetração de mercado \\
\hline $5^{\text {a }}$ & Porter & Novos concorrentes entrantes no mercado \\
\hline $6^{\text {a }}$ & Miles e Snow & Atitudes defensivas \\
\hline $7^{\text {a }}$ & Porter & Fornecedores \\
\hline $8^{\text {a }}$ & Porter & Clientes \\
\hline $9^{\text {a }}$ & Ansoff & Desenvolvimento de novos mercados \\
\hline $10^{\text {a }}$ & Porter & Serviços substitutos \\
\hline $11^{\text {a }}$ & Porter & Concorrentes atuais \\
\hline $12^{\text {a }}$ & Ansoff & Desenvolvimento de novos produtos \\
\hline $13^{\text {a }}$ & Miles e Snow & Atitudes reativas \\
\hline
\end{tabular}

Fonte: Elaborado pelos autores, 2016. 
Embora as estratégias de Porter sejam as mais citadas em artigos sobre serviços, conforme se observa no Quadro 6, sua predominância não foi constatada nesta pesquisa junto aos organizadores de eventos de Curitiba e Região Metropolitana.

Resumidamente, apresenta-se na sequência a Tabela 01, com as afirmativas que obtiveram as maiores médias, ou seja, que possuem a homogeneidade mais similar entre os 39 respondentes.

Tabela 1 - Afirmativas com Maior Homogeneidade dos 13 Blocos

\begin{tabular}{lc}
\hline Afirmativas com maior homogeneidade dos 13 blocos & Média \\
\hline 9.1 Não podemos ficar reféns de apenas um segmento da área de eventos. & $\mathbf{6 , 3 5}$ \\
\hline 12.5 Avaliamos nossa participação no mercado como capaz de manter a empresa em longo & $\mathbf{6 , 0 5}$ \\
prazo. & $\mathbf{5 , 9 7}$ \\
\hline 11.2 Busco facilitar as normas em minha empresa para torná-la mais eficiente. & $\mathbf{5 , 8 4}$ \\
\hline 6.4 Nem sempre podemos concorrer somente pelo preço. & $\mathbf{5 , 7 4}$ \\
\hline 5.1 Existem novas empresas atuando no segmento principal atendido por minha empresa. & $\mathbf{5 , 7 1}$ \\
\hline 10.2 Melhorar meus processos produtivos. & $\mathbf{5 , 5 6}$ \\
\hline 4.4 A qualidade dos serviços prestados por minha empresa está diretamente ligada à qualidade & $\mathbf{5 , 4 6}$ \\
de meus fornecedores. & $\mathbf{5 , 4 3}$ \\
\hline 3.4 Os clientes pressionam por preços baixos para fechar um contrato. & $\mathbf{5 , 2 0}$ \\
\hline 7.3 Estou capacitado para enfrentar a concorrência. & $\mathbf{5 , 1 5}$ \\
\hline 2.4 Tenho toda uma diferenciação de serviços em relação aos concorrentes. & $\mathbf{5 , 1 0}$
\end{tabular}

Fonte: Elaborado pelos autores, 2016.

Pode-se indicar que no levantamento das afirmativas a que obteve alta concordância foi a 9.1: "Não podemos ficar reféns de apenas um segmento da área de eventos", com 6,35, e esta foi a estratégia de diversificação proposta por Ansoff. Já a segunda maior homogeneidade com alta concordância foi na afirmativa 12.5: "Avaliamos nossa participação no mercado como capaz de manter a empresa em longo prazo", com 6,05, da estratégia de atitudes analíticas de Miles e Snow.

A terceira estratégia com maior homogeneidade foi a afirmativa 11.2: "Busco facilitar as normas em minha empresa para torná-la mais eficiente", com 5,97, sendo parte da estratégia de atitudes prospectivas de Miles e Snow. Em seguida, a afirmativa 6.4: "nem sempre podemos concorrer somente pelo preço", com 5,84, parte da estratégia de Ansoff de 
penetração no mercado.

Em quinto lugar, identifica-se a estratégia de Porter que trata de novos concorrentes entrantes no mercado junto à afirmativa 5.1: "Existem novas empresas atuando no segmento principal atendido por minha empresa", com 5,74.

Posteriormente, com maior homogeneidade foi a afirmativa 10.2: "melhorar meus processos produtivos", com 5,71, que é a estratégia de atitudes defensivas de Ansoff. Em sétima classificação ficou a afirmativa 4.4: "A qualidade dos serviços prestados por minha empresa está diretamente ligada à qualidade de meus fornecedores", com 5,56, uma estratégia de Porter sobre fornecedores.

Com a oitava maior homogeneidade ficou a afirmativa 3.4: "Os clientes pressionam por preços baixos para fechar um contrato", com 5,46, que é uma estratégia de Porter sobre clientes. Em continuidade tem-se a afirmativa 7.2: "No mercado local e regional minha empresa tem grande destaque e importância no principal segmento atendido", com 5,25, estratégia de Ansoff de desenvolvimento de novos mercados.

Na sequência, tem-se a afirmativa 2.4: "Tenho toda uma diferenciação de serviços em relação aos concorrentes", com 5,20, que é uma estratégia de Porter sobre serviços substitutos. Como décima primeira homogeneidade, a afirmativa 1.5: "Minha empresa já perdeu vendas para empresas concorrentes", com 5,15, é uma estratégia de Porter sobre concorrentes atuais.

Em penúltimo lugar, a afirmativa 8.5: "Existem oportunidades de desenvolver novos produtos, pelas mudanças tecnológicas e demográficas que surgem”, com 5,10. E, em último, a estratégia de Miles e Snow, atitudes reativas, cuja afirmativa diz: "em muitos casos o melhor é não tomar nenhuma estratégia”, com média de 5.053.

\section{CONSIDERAÇÕES FINAIS}

O mercado de eventos contribui para a economia de uma região com a geração de empregos, renda e impostos, além de atenuar os efeitos prejudiciais provenientes da sazonalidade, envolvendo o trabalho de diferentes empresas e profissionais. Para as empresas que atuam neste segmento em uma localidade os eventos servem como forma de atingir metas e objetivos financeiros. Investir na captação de eventos, sejam eles locais, regionais, nacionais ou internacionais, auxilia a localidade a desenvolver-se, maximizando o uso de sua infraestrutura, contribuindo para a qualidade de vida da região.

$\mathrm{Na}$ avaliação do contexto do mercado das empresas organizadoras de eventos e caracterização do seu perfil, percebeu-se a necessidade de qualificação dos profissionais que atuam na organização e promoção de eventos, principalmente seus gestores. É necessário que 
eles estejam aptos a tomarem decisões assertivas a fim de contribuir para a melhoria e crescimento do setor. Cabe aos gestores o desenvolvimento de uma visão prospectiva, colocando-a de frente às demandas para que seja possível ofertar serviços inovadores, competitivos e de qualidade percebida.

Em razão do cenário competitivo do setor de eventos decorre a necessidade de coletar dados sobre os concorrentes, seus produtos e serviços, haja vista que tais informações podem servir de subsídios para determinar as melhores formas de se posicionar estrategicamente face aos demais competidores. Acrescenta-se a isso a necessidade de manter-se atento às inovações e novas tendências, objetivando captar potenciais clientes a partir de nichos do mercado de eventos.

Da mesma forma, o uso de estratégias competitivas no setor de eventos possibilita às empresas encontrarem novos fornecedores ao saberem avaliar corretamente as novas tendências do setor, estipulando metas e objetivos de curto, médio e longo prazo. Tais objetivos podem ser conquistados com maior êxito quando as empresas deste segmento atuam de forma profissional, com oferta de produtos e serviços diversificados, diferenciados, inovadores e de qualidade.

Os principais resultados do trabalho mostram que os gestores conhecem bem o mercado e a concorrência, podendo indicar seus diferenciais competitivos, sabem o tamanho do mercado e que os concorrentes são numerosos tanto em tamanho quanto em poder.

Os gestores indicam que oferecem serviços além do principal segmento atendido para fazer frente a produtos substitutos e que aceitam sugestões dos clientes, embora isto acarrete encarecimento do serviço. Também que os clientes barganham por preços mais baixos, jogando uma empresa de eventos contra outras.

Tratando dos fornecedores, os entrevistados afirmam que trabalham com os mesmos há muito tempo e que sempre avaliam os fornecedores ao final de cada evento, pois sabem que a qualidade do serviço prestado está diretamente ligada aos seus fornecedores. Sobre os novos concorrentes que estão chegando ao mercado, os gestores conhecem as empresas e indicam que a principal barreira para estes concorrentes é a escala de prestação de serviços.

Tratando das estratégias de penetração no mercado, os gestores concordam que quanto maior é a oferta de mercado, maior é a possibilidade de sucesso e que quando o padrão de gastos dos consumidores se altera, cabe às empresas fazerem frente a estas mudanças. Sobre as estratégias de desenvolvimento de novos mercados, as empresas se consideram capacitadas para enfrentar a concorrência já que fazem investimentos em equipamentos, instalações e outros itens para cativar novos clientes. 
Para as estratégias de desenvolvimento de novos produtos, os respondentes indicaram que desenvolvem novos tipos de eventos para enfrentar a concorrência, e que já ofereceram serviços muito similares aos dos concorrentes para não perder um contrato. Abordando as estratégias de diversificação, os entrevistados afirmaram que ao longo dos anos os clientes também mudaram, obrigando a empresa a se atualizar, e que quando buscam atender a novos segmentos podem melhor planejar o futuro da empresa.

Sobre as estratégias adaptativas e quando assumem atitudes defensivas, a empresa desenvolve a distribuição das responsabilidades entre os colaboradores para melhor controlar os resultados, fazendo frente aos concorrentes com atitudes mais agressivas. Já para adotarem atitudes prospectivas as empresas se tornam mais flexíveis a novas ideias e novas formas de atuação e desenvolvem novas abordagens para conseguir clientes.

Respondendo sobre atitudes analíticas tomadas, os gestores afirmam que procuram saber onde e de que forma os principais concorrentes estão atuando no mercado, e que analisam os aspectos positivos e negativos dos concorrentes. As atitudes reativas foram a estratégia menos indicada pelas empresas, que afirmam que em muitos casos é melhor não tomar nenhuma estratégia.

Neste estudo procurou-se indicar as principais decisões gerenciais ligadas às estratégias competitivas que as empresas organizadoras de eventos devem utilizar para se manterem no mercado. Embora de forma empírica, elas podem ser estudadas e categorizadas em uma nomenclatura (teoria) que possa ser compreendida pelos pesquisadores do assunto. Assim, o estudo da aplicabilidade correta das estratégias existentes em uma empresa de eventos contribui para que outros gestores tenham acesso aos indicativos (indicadores) de decisões que podem ser tomadas, já que foram utilizadas e principalmente testadas no histórico administrativo das empresas pesquisadas.

Realizar eventos de forma eficiente é a meta de seus organizadores, buscando que o planejamento adequado cumpra os objetivos propostos a patrocinadores e participantes. Para os responsáveis pelas organizações que procuram uma oportunidade de divulgar seu negócio, os eventos, quando realizados em locais adequados, são uma opção de marketing que possibilita atingir o público de forma adequada e a um custo relativamente mais baixo do que opções mais populares como jornais, televisão, rádio, internet, entre outros.

Com base nos resultados é possível concluir que as empresas, de forma quase generalizada, não fazem um planejamento de longo prazo. Mesmo aquelas com maior número de funcionários, com gestores com formação em Administração ou Economia, agem à mercê dos acontecimentos, procurando resolver os problemas quando eles surgem. 
Apesar de as teorias de Porter serem as mais citadas em pesquisas de serviços, neste trabalho o destaque foi para a teoria de Ansoff, que os entrevistados usam, mesmo que de forma empírica, para tomar decisões que possibilitem o avanço econômico das empresas. Estas devem adequar-se às mudanças advindas de um ambiente competitivo e em mutação, onde somente os mais preparados para enfrentar crises irão se manter e prosperar.

Já ao analisar a utilização de estratégias competitivas em relação ao desempenho organizacional, verificou-se que as empresas utilizam estratégias de forma aleatória e não vinculadas a um planejamento estratégico formulado e discutido para obter o maior retorno e uma maior aplicabilidade, com possibilidade de retorno na resolução de problemas. Conforme surgem os problemas as empresas buscam a solução mais rápida e adequada a eles, ou seja, utilizam de forma empírica as estratégias.

Para verificar como são formuladas e operacionalizadas as estratégias competitivas pelas empresas organizadoras de eventos em Curitiba e Região Metropolitana, podem-se observar alguns resultados:

- em geral isto não se reflete no crescimento da empresa, visto que a grande maioria se manteve estabilizada nos últimos anos, com poucas empresas crescendo nesta época de problemas econômicos no Brasil;

- por outro lado, também se pode afirmar que se estas empresas não tivessem adotado diversas estratégias competitivas, possivelmente já teriam encerrado suas atividades;

- as estratégias competitivas propostas por Porter (1990), Ansoff (1990) e Miles e Snow (1978) são perceptíveis na forma de atuação das empresas organizadoras de eventos;

- o acirramento da concorrência faz com que as empresas que subsidiam suas decisões em estratégias já consolidadas possuam fatores que contribuem para a sua sobrevivência a longo prazo;

- o ambiente cada vez mais competitivo no segmento de eventos torna imprescindível uma administração profissional.

Os dados deste trabalho podem ser usados pelas empresas de forma prática, pois as informações podem auxiliar os gestores a tomar decisões baseadas em teorias já comprovadas e que contribuem para um planejamento de longo prazo mais assertivo.

As limitações do estudo estão relacionadas com a existência de poucos dados sobre empresas de organizações de eventos. Foram observadas outras limitações no estudo: a 
diversidade de empresas de eventos existentes, o que torna o estudo heterogêneo; a dificuldade de aplicar o mesmo questionário em empresas de portes e estruturas diferentes, pois envolvem realidades bem distintas; e a limitação do marco teórico, que foi de 2010 a 2015.

A precariedade se dá na análise de gestão das empresas de eventos e sobre as estratégias competitivas, o que reforça ainda mais a validade da proposta da presente pesquisa.

Indica-se para futuros estudos que seja delimitada uma tipologia específica de empresas como, por exemplo, formaturas, e a pesquisa seja aplicada apenas a elas, o que facilitará as comparações e possibilitará encontrar correlações entre variáveis de forma mais assertiva. Novos estudos também podem ser realizados analisando relações entre atuação dos profissionais e a relação do comportamento estratégico.

\section{REFERÊNCIAS}

Ansoff, H. I. (1990). Do planejamento estratégico à administração estratégica. São Paulo: Atlas.

Ansoff, H. I. (1991). A nova estratégia empresarial. São Paulo: Atlas.

Ansoff, H. I. (1977). Estratégia empresarial. São Paulo: McGraw-Hill.

Associação Brasileira de Empresas de Eventos - ABEOC. (2014). II Dimensionamento Econômico da Indústria de Eventos no Brasil 2013. Recuperado de

http://www.abeoc.org.br/2014/10/ii-dimensionamento-economico-da-industria-de-eventos-nobrasil/.

Barbosa, J. D., \& Teixeira, R. M. (2003). Gestão estratégica nas empresas de pequeno e médio porte. Caderno de Pesquisas em Administração, 10(3), 31-42.

Barney, J. B., \& Clark, D. N. (2007). Resource-based theory: creating and sustaining competitive advantage. New York: Oxford University.

Bernardi, L. A. (2003). Manual de empreendedorismo e gestão: fundamentos, estratégias e dinâmicas. São Paulo: Atlas.

Brasileiro, A. F., \& Morandi, T. A. (2014). As forças e estratégias de Michael Porter no ramo audiovisual: estudo de caso de uma produtora de São João del-Rei (MG). INTERCOM Sociedade Brasileira de Estudos Interdisciplinares da Comunicação. Revista Iniciacom, 6(1).

Canton, A. M. (2002). Eventos: ferramenta de sustentação às organizações do terceiro setor. São Paulo: Roca.

Carneiro, L. M. (2011). Política de apoio à captação de eventos internacionais no Brasil: análise do ranking ICCA entre 2003 e 2009. RBTur, 5(3).

Charles C., Snow, C. C., Lawrence, G., \& Hrebiniak, L. G. (1980). Strategy, distinctive competence, and organizational performance. Administrative Science Quartely, 25, 317-336. 
Chiavenato, I., \& Sapiro, A. (2009). Planejamento estratégico. (2a. ed.). Rio de Janeiro: Elsevier.

Coutinho, H. P. M., \& Coutinho, H. R. M. (2007). Turismo de eventos como alternativa para o problema da sazonalidade turística. Revista Eletrônica Aboré, 3.

Cronbach, L. J. (1951). Coefficient alpha and the internal structure of test. Psychometrika, 15(3), 297-334.

Ferreira, R. S., \& Wada, E. K. (2010). Eventos: uma alavanca de negócios como e porque implantar PEGE. São Paulo: Aleph.

Folha de São Paulo. (2016). Crescimento do setor de eventos cria oportunidades pelo Brasil. Recuperado em 08, novembro, 2016, de http://www1.folha.uol.com.br/

Forsythe, P. (2008). Modelling customer perceived service quality in housing construction. Engineering, Construction and Architectural Management, 15(5), 485-496.

Getz, D. (2008). Event tourism: definition, evolution, and research. Tourism management, 29(3), 403-428.

Gimenez, F. A., Pelisson, C., Kruger, E. G., \& Hayashi Jr, P. (1999). Estratégia em pequenas empresas: uma aplicação do modelo de Miles e Snow. Revista de Administração Contemporânea, 3(2), 53-74.

Goeldner, C. R., Ritchier, B., \& Macintosh, R. U. (2002). Turismo: princípios, práticas e filosofias. (8a. ed.). São Paulo: Bookman.

Gohr, C. F., Moretto Neto, L., \& Santana, E. (2002). Estratégias competitivas: um estudo no setor hoteleiro de Itapema/SC. Turismo - Visão e Ação, 4(10).

Hambrick, D. C. (1984). Some tests of the effectiveness and functional attributes of Miles and Snow's strategic types. Academy of Management Journal, 26(1), 05-26.

Hocayen-da-Silva, A. J. \& Teixeira, R. M. (2011). Hotelaria e adaptação estratégica: estudo comparativo de casos. VIII Convibra Administração - Congresso Virtual Brasileiro de Administração.

Instituto Brasileiro de Geografia e Estatística - IBGE. (2016). PIB cai 3,8\% e totaliza 5,9 trilhões. Recuperado em 08, novembro, 2016, de

https://agenciadenoticias.ibge.gov.br/agencia-sala-de-imprensa/2013-agencia-denoticias/releases/9610-em-2015-pib-cai-3-8-e-totaliza-r-5-9-trilhoes

Jaffe, E. D., Nebenzahl, I. D. \& Schorr, I. (2005). Strategic options of home country firms faced with MNC entry. Long Range Planning, 38(2), 183-196.

Jarvis, N., \& Blank, C. (2011). The importance of tourism motivations amongs port event volunteer satthe 2007 World Artistic Gymnastics Championships, Stuttgart, Germany. Journal of Sport \& Tourism, 16(2), 129-147.

Lawson, F. (2000). Congress, convention and exhibition facilities: planning, design and refurbishment. Architectural Press Publications: London. 
Long, P. T., \& Perdue, R. R. (1990).The economic impact of rural festivals and special events: assessing the special distribution of expenditures. Journal of Travel Research, 28(4), $10-14$.

Miles, R. E., \& Snow, C. C. (1978). Organizational strategy, structure and process. McGraw Hill.

Miles, R. E., \& Snow, C. C. (1994). Fit, Failure, and Hal of Fame. Free Press.

Nakane, A. (2013). Segurança em eventos. São Paulo: Aleph.

Nesheim, J. L. (2007). Diferencial competitivo. Rio de Janeiro: BestSeller.

Oliveira, D. P. R. (1991). Estratégia empresarial: uma abordagem empreendedora. (2a.ed.). São Paulo: Atlas.

Organização Mundial do Turismo - OMT. (1998). Barômetro Mundial do Turismo. Recuperado de http://www.unwto.org/facts/eng/pdf/barometer/UN WTO_Barom11_advance_january_en_excerpt.pdf

Organização Mundial do Turismo - OMT. (2011). Annual Report 2011. Recuperado em 15, setembro, 2015, de http://cf.cdn.unwto.org/sites/all/files/pdf/annual_report_2011.pdf

Pereira, B. C., \& Borges, M. P. (2006). Turismo de negócios: uma análise do setor em Piracicaba/SP. Caderno Virtual de Turismo, 6(4), 61-68.

Porter, M. (1986). Estratégia competitiva: Técnicas para Análise de Indústrias e da Concorrência. Rio de Janeiro: Campus.

Porter, M. (1990). Estratégia competitiva. São Paulo: Campus.

Reis, J. (2013). Sou produtor de eventos: diário de bordo para o aperfeiçoamento profissional. São Paulo, Rio de Janeiro: Senac Nacional.

Stadler, A., Arantes, E., \& RodermeL, P. (Orgs.). (2013). Marketing e finanças. Curitiba: InterSaberes.

Valor Econômico. (2016). PIB do Brasil cai 7,2\% em dois anos, pior recessão desde 1948. Recuperado em 08, novembro, 2016, de www.valor.com.br/brasil/4890366/pib-do-brasil-cai72-em-dois-anos-pior-recessao-desde-1948

Whittington, R. (2004). Estratégia após o modernismo: recuperando a prática. RAE - Revista de administração de empresas, 44, (4), 44-53.

Wright, P. L., Kroll, M. J., \& Parnell, J. (2000). Administração estratégica: conceitos. São Paulo: Atlas.

Zahra, S. A., \& Pearce II, J. A. (1990). Research evidence on the Miles-Snow typology. Journal of Management, 16(4), 751-768.

Zan, M. R. C. A. (2011). Patrocínio a eventos: o efeito sinérgico da comunicação integrada de marketing. São Caetano do Sul, SP: Difusão Editora.

Zanella, L. C. (2003). Manual de organização de eventos: planejamento e operacionalização. São Paulo: Atlas. 
Ziakas, V., \& Costa, C. A. (2011). The use of an event portfolio in regional community and tourism development: Creating synergy between sport and cultural events. Journal of Sport \& Tourism, 16, (2), 149-175.

Zobaran, S. (2012). Evento é assim mesmo: do conceito ao brinde. (3a. ed.). Rio de Janeiro: Ed. Senac Rio.

MAIOLI, M. R. \& TOMELIN, C. A. (2019). Estratégias competitivas praticadas por empresas de organização de eventos de Curitiba e região metropolitana - PR. Revista de Turismo Contemporâneo, 7(2), 240-259. https://doi.org/10.21680/2357-8211.2019v7n2ID16975 